\title{
Comparison of Diameter and Depth Morphometry in Human Acetabulum in Terms of Age and Gender: A Radiological Study
}

\author{
Mahmut Cay1, Deniz Senol2*, Mustafa Canbolat², Ismail Okan Yildirim³, \\ Evren Kose ${ }^{2}$ and Davut Ozbag² \\ 1Uşak University, Faculty of Medicine, Department of Anatomy, Uşak, Turkey \\ 2İnönü University, Faculty of Medicine, Department of Anatomy, Malatya, Turkey \\ 3İnönü University, Faculty of Medicine, Department of Radiology, Malatya, Turkey
}

\section{Research Article}

Volume 1 Issue 2

Received Date: June 21, 2017

Published Date: June 28, 2017

*Corresponding author: Deniz Senol, Department of Anatomy, İnönü University Faculty of Medicine, 44280 Malatya, Turkey, Tel: +090 50644706 86; E-mail: deniz.senol@inonu.edu.tr

\section{Abstract}

The anatomical parameters of hip joint will be of immense importance to orthopedicians, radiologists and prosthetists. These parameters help in designing patient specific implants and can be utilized to understand etiopathogenesis of osteoarthritis. The objective of this study is to compare acetabular diameter (AD) and acetabular depth (Depth) morphology in humans in terms of age and gender. This study was conducted with the AD and Depth measurements of 80 patients, 40 males and 40 females, over CT. Patients between the ages 20 and 40 were included in the study. Measurements were performed unilaterally, from the left side Mann-Whitney U test and Spearman Correlation Analysis were used for data analysis with IBM SPSS Statistics 22.0 for Windows. In terms of AD measured over CT images, statistically significant difference was found between males and females $(\mathrm{p}<0.05)$, while no difference was found in terms of Depth $(\mathrm{p}>0.05)$. According to the correlation analysis conducted, no statistically significant correlation was found between age and $A D$ and Depth in males and females ( $p>0.05)$. A positive significant correlation was found between $A D$ and Depth in males and females $(\mathrm{p}<0.05)$. We believe that the results of our study will contribute to studies about hip arthroplasty applications. In addition, we believe that a data base will be formed about this subject related with our region.

Keywords: Hip bone; Acetabular diameter; Acetabular depth; CT, Morphology 


\section{Introduction}

Hip joint is one of the most important weight carrying joints of the body. Originally, hip joint was referred to as ball and socket joint; however, it is being referred to as rotational conchoids at the moment [1]. Acetabulum is the name given to the concave on the medial side of the hip joint [2]. In healthy people, head of the femur meets with this concave [3].

Acetabulum is formed from the os ilium, os ischium and os pubis parts of os coxae. The lower part of acetabulum which is not in the shape of full circle ends with inc. acetabuli. This incisura continues upward with fossa acetabuli and the half-moon shaped surface between inc. acetabuli and fossa acetabuli which is called facies lunata is the part that meets the head of the femur $[4,5]$. At the centre of the joint that is in the lower and mid part of inguinal ligament head of the femur forms a joint with the cup shaped acetabulum [6]. This joint enables us to make flexion, extension, adduction and abduction moves [7]. Environment and ethnic factors cause changes about acetabulum morphology $[8,9]$.

Hip joint osteoarthritis is common in western countries and it has different etiology. An incongruous joint is more inclined to the development of degenerative changes than a normal joint anatomy [10]. Hip osteoarthritis is estimated to be caused by acetabular dysplasia with a rate of $25-40 \%$. Hip with dysplasia is also associated with acetabular depth [11]. It is clinically important to have clear parameters that reflect our society about acetabulum morphology in hip arthroplasty applications, approaches to hip fracture and hip dysplasia [12].

Anatomy of proximal femur and acetabulum are very important in total hip replacement surgery. The objective of this study is to compare AD and Depth morphology in humans in terms of age and gender.

\section{Materials and Methods}

In this study, $\mathrm{AD}$ and Depth measurements of 80 patients, 40 males and 40 females, were made over CT at İnönü University T.Ö.T.M. Radiology department. Males and females between the ages 20 and 40 were included in the study. Males's average of age was $29.25 \pm 5.98$, while females's average of age was $30.97 \pm 6.14$.

Care was taken for the female and males included in the study to be sedentary and not to have any problems about the lower extremity. CTs of patients who had been admitted to hospital for an abdominal problem were used in the study. The patients with surgical intervention, those with an orthopedic problem and those who had undergone acetabular dysplasia and hip arthroplasty were excluded. AD and Depth were performed unilaterally, from the left side (Figure 1).

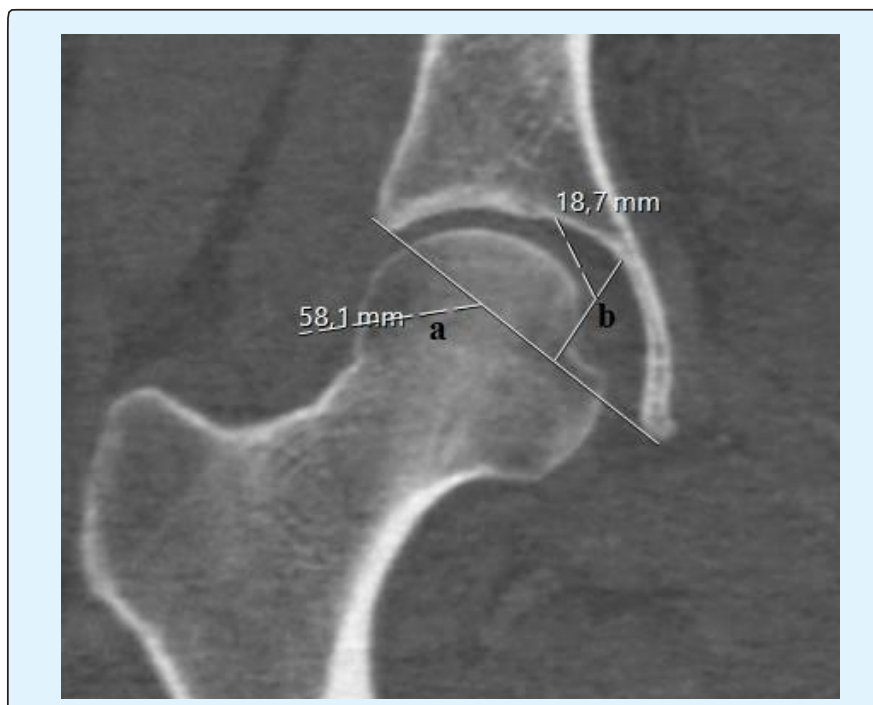

Figure 1: Measurements over CT; a: AD, b: Depth.

AD; Acetabular diameter is the name given to the distance between the acetabular ridge nearest to the body of ischium and anterior iliac margin converging the acetabular ridge. Depth; Across the diameter of the acetabulum, a thin metallic strip was placed [9].

Statistical Analysis: Shapiro-Wilk test was used to analyze whether the data were normally distributed. Mann-Whitney U test and Spearman Correlation Analysis were conducted for data analysis. Arithmetic mean (X) and standard deviation (sd), minimum (Min) and maximum (Max) value of the data were found and significance level was accepted as $\mathrm{p}<0.05$. IBM SPSS Statistics 22.0 for Windows package program was used for statistical analyses.

\section{Results}

In measurements obtained from all CT images, average $\mathrm{AD}$ was found as $60.82 \pm 4.22 \mathrm{~mm}$, while average Depth was found as $18.28 \pm 2.87 \mathrm{~mm}$.

Measurement results showed that AD was $63.38 \pm 3.91$ $\mathrm{mm}$ in males, while it was $58.25 \pm 2.72 \mathrm{~mm}$ in females. Average depth was $18.99 \pm 2.34 \mathrm{~mm}$ in males, while it was $18 \pm 1.94 \mathrm{~mm}$ in females. Mann-Whitney $\mathrm{U}$ test was conducted to find out whether there were statistical 
differences between males and females whose AD and Depth measurements were conducted over CT images. According to the results of Mann-Whitney $U$ test, statistically significant difference was found between males and females in terms of $A D(p<0.05)$, while no differences were found in terms of Depth ( $p>0.05)$, (Table 1).

\begin{tabular}{|c|c|c|c|c|c|c|c|}
\hline \multirow{2}{*}{ Parameter } & \multicolumn{3}{|c|}{ Male } & \multicolumn{3}{|c|}{ Female } & \multirow[b]{2}{*}{$p$} \\
\hline & $X \pm s d$ & Min & Max & $X \pm s d$ & Min & Max & \\
\hline AD & $63.38 \pm 3.91$ & 54 & 71.5 & $58.25 \pm 2.72$ & 53.5 & 63.8 & .000 \\
\hline Depth & $18.99 \pm 2.34$ & 14 & 24.5 & $18 \pm 1.94$ & 13.1 & 22.5 & .106 \\
\hline
\end{tabular}

Table 1: $\mathrm{X} \pm \mathrm{sd}$, Min and Max values and Mann-Whitney $\mathrm{U}$ test results of AD and Depth obtained from CT images of men and women.

Correlation analysis was conducted on to find out how $\mathrm{AD}$ and Depth differed in males and females included in the radiological study in terms of age. Correlation analysis results did not show a statistically significant correlation between $A D$ and Depth ( $p>0.05)$. A positive significant correlation was found between $\mathrm{AD}$ and Depth in males and females $(\mathrm{p}<0.05)$, (Table 2$)$.

\begin{tabular}{|c|c|c|c|c|c|c|c|}
\hline \multicolumn{2}{|c|}{ Parameter } & \multicolumn{3}{c|}{ Male } & \multicolumn{3}{c|}{ Female } \\
\cline { 3 - 7 } & & Age & AD & Depth & Age & AD & Depth \\
\hline \multirow{2}{*}{ Age } & $\boldsymbol{r}$ & 1 & 0.032 & 0.183 & 1 & 0.209 & 0.151 \\
& $\boldsymbol{p}$ & - & 0.843 & 0.259 & - & 0.195 & 0.353 \\
\hline \multirow{2}{*}{ AD } & $\boldsymbol{r}$ & 0.032 & 1 & 0.475 & 0.209 & 1 & 0.461 \\
& $\boldsymbol{p}$ & 0.843 & - & $\mathbf{0 . 0 0 2}$ & 0.195 & - & $\mathbf{0 . 0 0 4}$ \\
\hline \multirow{2}{*}{ Depth } & $\boldsymbol{r}$ & 0.183 & 0.475 & 1 & 0.151 & 0.461 & 1 \\
\cline { 2 - 8 } & $\boldsymbol{p}$ & 0.259 & $\mathbf{0 . 0 0 2}$ & - & 0.353 & $\mathbf{0 . 0 0 4}$ & - \\
\hline
\end{tabular}

Table 2: Correlation analysis results between age and AD and Depth in men and women.

\section{Discussion}

Prosthetists and biomechanical engineers use anatomical parameters of hip joint while designing the best possible population specific prosthesis for hip replacement surgery. The complications caused by the mismatch of the prosthesis in total hip replacement surgeries can be prevented this way. Many prosthetists were found to design prosthesis by considering the parameters available from Western countries. On the contrary, this study will present parameters characteristic of Turkish population and help prosthetists to design much better prosthesis.

Aktas, et al. reported that the morphometry of the hip joint displayed ethnical differences [13]. They measured the acetabular depth in various age groups and found depths between 10.00 and $11.1 \mathrm{~mm}$. Arsic, et al. found difference between males and females in terms of depth in their study they conducted on CT images [14]. In this study, we found statistically significant difference between $\mathrm{AD}$ measurements between males and females.
In their radiological study, Park and Im, found Depth as $11.8 \pm 2.9 \mathrm{~mm}$ in males whose average of age was $47.5 \pm$ $17.5 \mathrm{~mm}$ and as $11.4 \pm 2.5 \mathrm{~mm}$ in females whose average of age was $55.6 \pm 18.5 \mathrm{~mm}$ [15]. Devi and Philip found Depth values between $21.8 \mathrm{~mm}$ and $34.6 \mathrm{~mm}$ and the average as $28.32 \pm 1.32 \mathrm{~mm}$ [10], Tastekin Aksu, et al. found Depth values between $22.6 \mathrm{~mm}$ and $38.6 \mathrm{~mm}$ and the average as $29.49 \pm 4.2 \mathrm{~mm}$ [6], Parmara, et al. found Depth values between $19.07 \mathrm{~mm}$ and $32.13 \mathrm{~mm}$ and the average as $29.49 \pm 4.2 \mathrm{~mm}$ [16]. Although the Depth results of this study do not completely match with the results of the above mentioned studies, they are similar.

Devi and Philip found AD values between $42.8 \mathrm{~mm}$ and $61.5 \mathrm{~mm}$ and the average as $50.99 \pm 1.99 \mathrm{~mm} \mathrm{[10],}$ Tastekin Aksu, et al. found AD values between $44.8 \mathrm{~mm}$ and $65.5 \mathrm{~mm}$ and the average as $54.29 \pm 3.8 \mathrm{~mm}$ [6], Parmara, et al. found AD values between $42.54 \mathrm{~mm}$ and $56.60 \mathrm{~mm}$ and the average as $42.54 \pm 3.6 \mathrm{~mm}$ [16]. The 
$\mathrm{AD}$ results in this study were found to be similar to those in aforementioned studies.

Tastekin Aksu, et al. found positive significant correlation between AD and Depth [6]. This result is in parallel with the results of our study. In their study they conducted on Chinese population, Zeng, et al. did not find any correlations between $\mathrm{AD}$ and Depth in females with an average age of $44.2 \pm 5.27$ and in males with an average age of $48.2 \pm 8.47 \mathrm{~mm}$ [17]. This result is not in parallel with the results of our study. Many authors like Croft, et al. Lau, et al. Smith, et al. Lane, et al. and Lequesne, et al. studied $\mathrm{AD}$ on CTs. As a result their studies show much lower values as compared to present study values [18-22].

We believe that the differences between the results of our study and other studies are related with environmental and ethnic factors. Other studies on this subject will clarify the subject. Knowing the morphology

of acetabulum morphology is a prerequisite to understand the mechanism of hip joint. We believe that the results of our study will contribute to studies about hip arthroplasty applications. In addition, we believe that a data base will be formed about this subject related with our region.

\section{References}

1. Menschik F (1997) The hip joint as a conchoid shape. J Biomech 30(9): 971-973.

2. Standring S (2005) Gray's Anatomy. 39th (Edn.), Elsevier Churchill Livingstone. Pp: 1421.

3. Denham RA, Alexander LW (1957) Arthroplasty of the hip. J Bone Joint Surg 39B: 614-622.

4. Arıncı K, Elhan A (2006) Anatomi (I. Cilt). Ossa Membri Inferioris-Acetabulum. Ankara: Güneș Kitabevi. Pp: 19.

5. Ergun M, Hayran M (2014) Anatomi. In: Apaydın N, editor. Alt Ekstemite Kemikleri. Ankara: MN Medikal \& Nobel Tıp Kitabevi. Pp: 101.

6. Taştekin Aksu F, Gülriz Çeri N, Arman C, Tetik S (2006) Morphology And Morphometry of The Acetabulum. DEÜ Tip Fakültesi Dergisi 20(3): 143148.
7. Javadekar BS (1961) A study of measurements of femur with special reference to sex. Journal of Anatomical Society of India 10: 25-27.

8. Govsa F, Ozer MA, Ozgur Z (2005) Morphological features of the acetabulum. Arch Orthop Trauma Surg 125: 453-461.

9. Dhindsa GS, Poonam Singh, Zora Singh (2013) Acetabulum: a morphometric study. J Evol Med Dental Sci 5(2): 659-665.

10. Devi TB, Philip C (2014) Acetabulum-Morphological and Morphometrical Study. RJPBCS 5(6): 793-799.

11. Murray RO (1965) The etiology of primary osteoarthritis of the hip. Br J Radiol 38(455): 810824.

12. Benazzi S, Maestri C, Parisini S, Vecchi F, Gruppioni $G$ (2008) Sex assessment from the acetabular rim by means of image analysis. Forensic Sci Int 180(1): 58.e1-58.e3.

13. Aktas S, Pekindil G, Ercan S, Pekindil Y (2000) Acetabular dysplasia in normal Turkish adults. Bull Hosp Jt Dis 59(3): 158-162.

14. Arsić S, Ilić D, Mitković M, Tufegdžić M, Janković S, et al. (2013) The Study of Morphological Parameters of Human Acetabulum Significant for Hip Arthroplasty. The $2^{\text {th }}$ International Conference Mechanical Engineering in XXI Century, Sirbia. June 20-21, pp: 115-120.

15. Park JM, Im G (2011) The Correlations of the Radiological Parameters of Hip Dysplasia and Proximal Femoral Deformity in Clinically Normal Hips of a Korean Population. Clin Orthop Surg 3(2): 121-127.

16. Parmara G, Rupareliab S, Patelc SV, Patelb SM, Jethvaa N (2013) Morphology and Morphometry of Acetabulum. Int J Biol Med Res 4(1): 2924-2926.

17. Zeng Y, Wang Y, Zhu Z, Tang T, Dai K, et al. (2012) Differences in acetabular morphology related to side and sex in a Chinese population. J Anat 220(3): 256-262.

18. Croft P, Cooper C, Wickham C, Coggon D (1991) Osteoarthritis of the hip and acetabular dysplasia. Annals of the Rheumatic Diseases 50: 308-310. 
19. Lau EMC, Lin F, Lam D, Silman A, Croft P (1995) Hip osteoarthritis and dysplasia in Chinesemen. Ann Rheum Dis 54(12): 965-969.

20. Smith RW, Egger P, Coggon D, Cawley MID, Cooper C (1995) Osteoarthritis of the hip joint and acetabular dysplasia in women. Ann Rheum Dis 54(3): 179181.
21. Lane NE, Nevitt MC, Cooper C, Pressman A, Gore R, et al. (1997) Acetabular dysplasia and osteoarthritis of the hip in elderly white women. Ann Rheum Dis 56(10): 627-630.

22. Lequesne M, Malghem J, Dion E (2004) The normal hip joint space: variations in width, shape and architecture on 223 pelvic radiographs. Ann Rheum Dis 63(9): 1145-1151. 